\title{
Maintaining a high-quality, cost- effective journal collection
}

\author{
By Dawn Bick
}

Director, Collection Development

Houston Academy of Medicine-

Texas Medical Center Library

\author{
and Reeta Sinha \\ Collection Development Assistant \\ Houston Academy of Medicine- \\ Texas Medical Center Library
}

\section{Use this practical technique to make your serial}

\author{
retention decisions.
}

$\mathbf{R}$ ising journal subscription costs and the decreasing purchasing power of serials budgets make it imperative for collection managers to spend their dollars as wisely as possible. A costbenefit ratio for each journal title can be determined on the basis of use and other critical retention factors. At the Houston Academy of MedicineTexas Medical Center Library we have determined that this ratio effectively supports retention and cancellation decisions.

\section{A cost-benefit ratio for each journal title can be determined on the basis of use and other critical retention factors.}

Those of us who have had the experience of cancelling journal titles realize the importance of having use data at hand in order to make sound cancellation or retention decisions. Ironically, use data are commonly not available for technical or logistical reasons, or both. Even if use data are available, they alone cannot be the basis of a cancellation or retention decision. Suppose five titles show relatively little use, and each supports a program or area of research in your institution. If you could afford to retain only two of them, which ones would they be? How would you justify your decisions? Raw use data do not expedite decisions in this case. But, if the use data were to be weighted by factoring in other journal worth criteria such as indexing, local availability, local contributors, impact factor etc., then one could compute a costbenefit ratio for each title. This ratio would give the support needed for cancellation or retention decisions.

\section{SERIALS Database}

In order to locate in one central area the data essential for providing support for journal decisions, a database of all active serial titles was developed. The SERIALS database lists all currently received journal and monographic serial titles and is updated on an ongoing basis as titles are added to the collection and/or cancelled. The initial list of titles and ISSNs was transferred in ASCII format from the library's serials control system to a database management system. The DBMS in current use is Paradox, and the SERIALS database now contains some 3,000 journal titles.

The data fields that have been utilized to store information about each title include identifiers and cost, as well as the criteria that are used to evaluate the journals' worth. The data were gathered from various sources, compiled on workforms, and then entered into the database. Unfortunately, most of the data were not available electronically such that ASCII files could be loaded into the database; these data had to be keyed in. The initial keying was labor-intensive, but updating has been smooth and efficient, as it has been integrated with 
the workflows of the Serials and Collection Development Departments.

\section{Ongoing journal use study}

Since August of 1989, the library has been studying in-house journal use. The in-house use data in combination with checkout data are central to the Library's journal evaluation decision support system.

The objective of the study is to monitor in-house uses of journal titles over consecutive one-year periods. Since no previous data were available, it was acknowledged that the ideal study design would be one in which in-house use statistics would be collected for every hour that the library was operational. The reality is that the resulting workload is unmanageable and impractical. Thus, the current survey is a descriptive study designed to collect inhouse use data for bound and unbound journal issues from a representative sample of the Library's operational hours over consecutive 12 -month periods. These periods correspond to the library's fiscal year, Septmber 1 to August 31 .

The study population consists of a stratified random sample of one-hour study segments drawn from the total numbers of hours the library's in operation during a given month. Each month, the stratified random sample is obtained by arbitrarily dividing the population (i.e., total number of operational hours) into strata designated as "morning hours," "afternoon hours," and "evening hours" and numbering all the hours in each. For example, there may be 122 "morning hours" in the month. Then a random sample of the numbered one-hour study segments is drawn from each stratum. This methodology reduces the sample variances so the population estimates obtained are more precise.

The required sample sizes are calculated each month in order to obtain accurate estimates of population statistics, such as average number of journal uses. In general, choosing a sample size requires (1) knowledge of population variances based on previously collected data and (2) defining limits for the tolerated level of error. ${ }^{\mathrm{I}}$ For this study, estimates should be accurate within one journal use and, since no previous data were available, population variances are estimated using the range of uses possible for each stratum. For the duration of the study, monthly samples have represented $8 \%-10 \%$ of total operational hours per month.

The data collection procedure involves a pick-up of all unshelved journals prior to start of each onehour sampling period. Then, journals used by the library's clients are allowed to accumulate during the period and are collected at the end of the hour. The bar codes of these collected journals are wanded into the library's automated system prior to reshelving. Thus, in-house uses by journal title are tabulated by the library's automated system.

The fact that participation in the journal use study continues to be a positive experience for the shelving staff helps to ensure the reliability of the data collected. The shelvers have been able to incorporate the data collection procedure into their daily routine and look forward to the study segments. It has been a morale booster for them to be taking part in an important library project, and they have welcomed the opportunity to receive handson experience using the library's automated system. From the investigator's point of view, it has also been encouraging to learn that the shelvers have been meticulous about collecting data, to a point beyond the general instructions given.

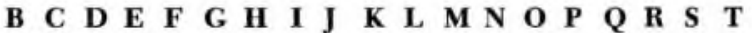

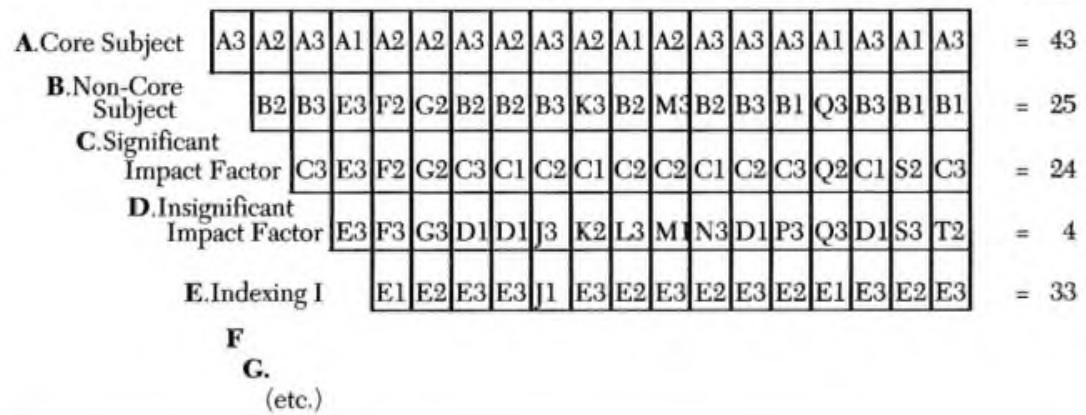

Score 


\section{Factor}

Weight

Weight

Normalized/100

Indexing I (I,SI,HLI,CINAIIL)
Core Subject
Indexing II (BIO,SCI,CC,PSYCH)
Medical Center Holdings - no
Significant Impact Factor
Library - only copy
Library Holdings - long
Indexing III (CHEM,EM,OTHER)
Regional Holdings - no
Non-Core Subject
Houston-Area Holdings - no
Full-Text Access - no
Library Holdings - short
Indexing IV (not indexed)
Medical Center Holdings - yes
Houston-Area Holdings - yes
Insignificant Impact Factor
Regional Holdings - yes
Full Text Access - yes
Library - duplicate copy

$\begin{array}{rr}37.0 & 11.5 \\ 37.0 & 11.5 \\ 32.0 & 10.0 \\ 24.0 & 7.5 \\ 23.5 & 7.3 \\ 22.6 & 7.0 \\ 20.8 & 6.5 \\ 19.3 & 6.0 \\ 17.3 & 5.4 \\ 16.8 & 5.2 \\ 16.0 & 5.0 \\ 12.6 & 3.9 \\ 8.6 & 2.7 \\ 7.0 & 2.2 \\ 6.0 & 1.9 \\ 5.8 & 1.8 \\ 5.5 & 1.7 \\ 5.0 & 1.6 \\ 4.0 & 1.2 \\ .5 & .2\end{array}$

The library's automated system compiles monthly statistics generating a list of journal titles with associated in-house and checkout use data. The use statistics are then stored in a data field in the SERIALS database so that usage can easily be factored in with the other evaluation criteria for individual journal titles.

\section{Developing journal evaluation criteria}

The basic criteria used to determine the worth of any journal title were weighted and ranked in order of importance using an evaluation matrix described by Mudge. ${ }^{2}$ The advantage of using the matrix approach is that the weighting of journal evaluation criteria is an objective and relative process rather than an arbitrary one. These weights apply specifically to the institution in which they were determined and they necessarily reflect collection development policy priorities. It is anticipated that these weights would change only as the collection development policy changes.

The evaluation matrix is designed so that only two criteria are compared at a time. For each pair of criteria, first determine which is the more important for retention of a journal title and then indicate whether the difference in importance is major, medium, or minor-assigning the number 3 for a major difference in importance, 2 for a medium difference, and 1 for a minor difference. For each comparison, two questions were asked: "Which is the factor that is more likely to make you want to retain a title?" and "Is the difference in importance major, medium, or minor?" A major difference in importance is obvious and the decision is almost instantaneous. A medium difference in importance requires a relatively short period of time for a decision. A minor difference in importance takes a considerable amount of time for a decision; but you are forced to decide.

For example, Figure 1 shows part of the matrix we used. The letters listed across the top of the matrix correspond to the underlined criteria listed down its side. To start off, factor A, "Core Subject," was compared to B, "Non-Core Subject," at the top of the matrix. Factor A was considered to be more important in retention of a title than B, so A was entered into the first cell. The number 3 was entered beside it indicating a major difference in importance. Working across the first row of cells, A was then compared to C, "Significant Impact Factor," and then to $\mathrm{D}$, etc., until it had been compared to all of the criteria listed across the top of the matrix. Likewise, $\mathrm{B}$ in the next row down was compared to $\mathrm{C}, \mathrm{D}, \mathrm{E}$, etc., in turn. The process continued until each factor was compared to all of the other criteria. After the matrix is complete, a score for each row of criteria is obtained by summing the numbers indicating importance $(1,2$, or 3$)$. For example, in Figure 1, all of the As were totalled 
to get a score of 43 , all of the Bs gave a total of 25 , etc. For our purposes, the matrix was completed individually by six members of a serials committee. Their numerical scores for each factor were averaged to obtain the final weight used. The average weight for factor $A$ was 37 , the average weight for $B$ was 16.8 , etc.

These weights were normalized to a base of 100 (see Table 1). The normalization was accomplished by totalling all of the criteria weights (total weights $=321.3$ ) and then using this total in the formula:

$$
\frac{\text { criteria weight }}{\text { total weights }}=\frac{\mathrm{x}}{100}
$$

For example, the calculation of the normalized weight $(x)$ for Indexing $I$ is:

\begin{tabular}{|c|c|c|}
\hline 37 & $=$ & $\mathrm{x}$ \\
\hline$\overline{321.3}$ & & 100 \\
\hline$x$ & $=$ & 11.5 \\
\hline
\end{tabular}

Table 2: PARADOX WORKSHEET FOR SERIAL TITLES

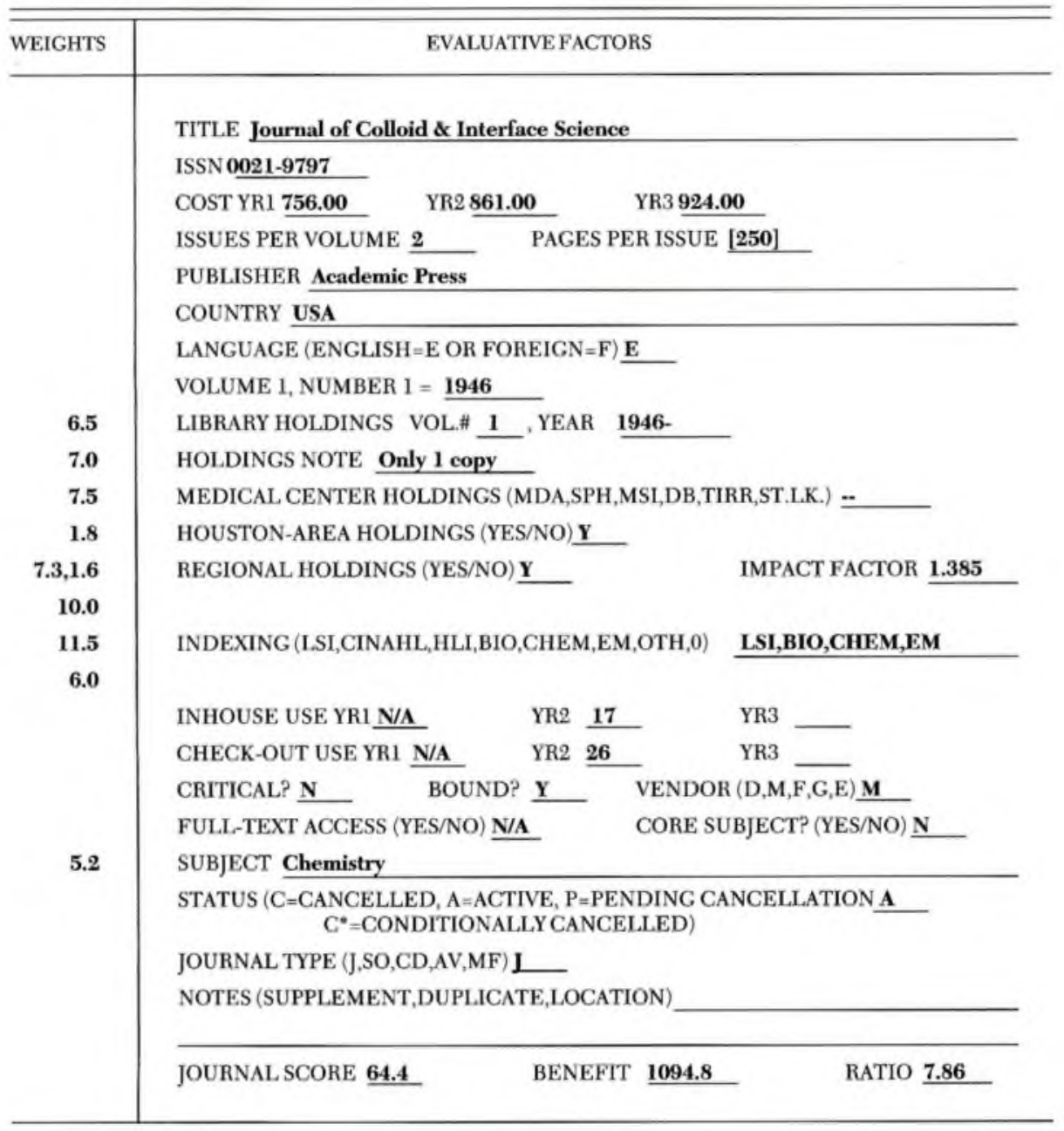

Numerical weight factors are listed to the left of each factor. The numerical factor weights pertaining to a particular title are added together to obtain a Journal Score. The scores for each title are computed and stored in the SERIALS database. 
Cost-Benefit

Title

Ratio

1. Chemical \& Engineering News

.82

2. Joumal of the American Chemical Society

2.18

3. Journal of Chemical Information \& Computer Sciences

5.65

4. Magnesium

5. Journal of Heterocyclic Chemistry

6.21

6. Journal of Physical Chemistry

6.73

7. Accounts of Chemical Research

7.09

7.37

8. Journal of Colloid \& Interface Science

7.86

9. Biopolymers

8.79

10. Angewandte Chemie

9.01

11. Journal of Chemical Physics

10.67

12. Macromolecules

14.71

13. Joumal of the Chemical Society. Faraday Transactions

16.85

14. Inorganic Chemistry

15. Journal of the Chemical Society. Perkins Transactions II

19.39

20.86

16. Biological Trace Element Research

22.09

17. Chemical Senses

26.46

18. Journal of the Chemical Society Dalton Transactions 28.09

19. The Analyst

29.99

20. Acta Chemica Scandinavica. Series A.

Physical \& Inorganic Chemistry

41.36

21. Journal of the Chemical Society. Chemical Communications 173.73

\section{Determining the journal score}

Once the evaluation criteria weights have been established, they can be applied to individual journal titles to determine a Journal Score for each. In the example shown in Table 2, the applicable numerical weights are listed to the left of each evaluation factor. For example, since the Library has relatively long holdings for the Journal of Colloid \& Interface Science, the weight of 6.5 has been assigned using the evaluation factor "Library Holdings-long" from Table l. Similarly, since the title is indexed by the National Library of Medicine's List of Serials Indexed for Online Users, Biological Abstracts, Chemical Abstracts, and Excerpta Medica, the established weights for the evaluation criteria "Indexing I" (11.5), "Indexing II" (10.0), and "Indexing III" (6.0) from Table 1 have been assigned.

Notall of the weights listed in Table 1 will be used when evaluating individual journal titles. Bynature, some pairs of evaluation criteria are mutually exclusive. For example, in the use of the criteria "Core Subject" and "Non-Core Subject" from Table 1, only one of these factors will apply for any given title since the subject of a title cannot be both core and non-core. In our example in Table 2, the subject "Chemistry" is considered to be non-core for our
Library; therefore, the weight of 5.2 has been assigned. Similarily, had the title only been indexed by Excerpta Medica, "Indexing III" from Table 1 would have been the only applicable evaluation factor for indexing. Therefore, only the weight of 6.0 would have been assigned.

Once all of the evaluation criteria have been assigned their respective weights, a Journal Score for each title can be determined by simply adding the weights. For our library, the scores for each title are computed and stored in the SERIALS database.

\section{Decision support}

To obtain the perceived benefit of a journal the Journal Score is multiplied by Use:

BENEFIT = Use $\mathrm{x}$ Journal Score.

According to this formula, since the score of a journal stays the same, Benefit increases as Use increases. In the example given in Table 2, the Inhouse use for Year 2 (17) was multiplied by the Journal Score (64.4) to obtain a Benefit of 1094.8.

Next, the formula for determining the cost-benefit ratio of a journal was developed. The annual subscription Cost is divided by Benefit and then multiplied by 10 just to make the numbers more manageable. 
COST-BENEFIT ratio $=($ COST $/$ BENEFIT $) \times 10$

Again, taking the example in Table 2, the Cost for Year $2(\$ 861.00)$ was divided by the journal's Benefit (1094.8) and multiplied by 10 to obtain the rounded off Cost-Benefit Ratio of 7.86.

This resulting ratio reflects the desirability of a journal. A journal with a high Benefit value is more desirable. Therefore, as Benefit increases, according to the formula, the cost-benefit ratio decreases. In other words, journal desirability increases as the cost-benefit ratio decreases. Table 3 shows a list of selected journals ranked in order of present desirability in our library.

\section{Conclusion}

Having the ability to produce, on demand, a list of the library's current journal titles ranked in order of desirability is a major step toward maintaining a high-quality journal collection which meets the needs of the clientele. Should the library have to cancel titles, faculty and other interested parties can be supplied with lists of journal titles, sorted by subjectand ranked by desirability. Decisions can be supported in an objective way. Other collection management concerns, including purchasing duplicate subscriptions, remote storage, and preservation decisions, can also be supported

'George W. Snedecor, and William G. Cochran, Statistical Methods, 7th ed. (Ames, Iowa: Iowa State University Press, 1980), 53.

${ }^{2}$ Arthur E. Mudge, Value Engineering: A Systematic Approach (New York: McGraw-Hill, 1971), 68-74.

Mudge, one of the pioneers in value engineering, describes a systematic approach for comparative analysis of a product. This approach includes using an evaluation matrix which compares the relative importance of the basic functions of each product being studied. We have used the evaluation matrix technique to compare the relative importance of basic worth criteria for the journals being studied.

\section{"Some librarians decide to consolidate their business with one serials vendor because they appreciate the benefits of dealing with a single representative. We're consolidating as many titles as we can through Faxon for an even more simple reason.

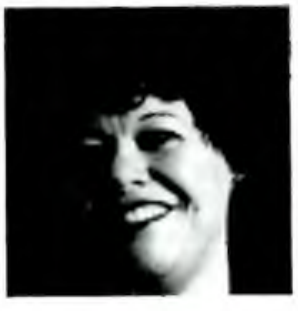

I've never asked Faxon for anything I baven't gotten."

-Dina Giambi, Head of AcQuisitions and Serials, Kent StaTe University

Helping you manage your world of information. 